\title{
Characterization and Mechanical Properties of the ZA-12 Hybrid Composites Reinforced with Nano Ceramic Particles
}

\author{
Aveen K. Yawer ${ }^{a *}$, Niveen J. Abdulkader ${ }^{b}$ \& Dr. Ahmed A. Zainalaadbeen ${ }^{c}$ \\ ${ }^{a}$ Materials Engineering Department, University of Technology, Baghdad -Iraq \\ mae.19.43@grad.uotechnology.edu.iq \\ ${ }^{\mathrm{b}}$ Materials Engineering Department, University of Technology, Baghdad -Iraq \\ 130012@uotechnology.edu.iq \\ ${ }^{\mathrm{c}}$ Materials Engineering Department, University of Technology, Baghdad -Iraq \\ 130028@uotechnology.edu.iq \\ *Corresponding author.
}

Submitted: 08/12/2020

Accepted: 11/02/2021

Published: 25/04/2021

\section{K E Y W O R D S}

ZA-12 alloy, Stir

Casting, Hybrid

Composite,

Nanoparticles, Hardness,

Wear Rate and

compression strength.

\section{A B S T R A C T}

In this work, nanosized Boron nitride and silicon carbide reinforced ZA 12 matrix hybrid composites were produced using stir casting technique with using of aluminum scrap (AA 2024), pure Al (electrical wires) and zinc scraps. Microstructure Observation was revealed by using scanning electron microscopy, and the analysis showed a uniform distribution of ( $\mathrm{SiC}$ and $\mathrm{BN}$ ) hybrid nanoparticles for the $\mathrm{Zn}-\mathrm{Al}$ matrix. Also, an optical microscope was used to display the dendritic structure and reinforcement particles that dispersed uniformly in the matrix. Mechanical tests results confirmed that the hardness and the compression was increased with increasing the hybrid nanoparticle's percentage, whereas the wear rate decreased as the reinforcing materials increased. Since nanoparticles restrict dislocation movement, the mechanical properties are enhanced. The improvement ratio in hardness after addition was $26 \%$., and in wear rate was $24 \%$ and for the compression strength the improvement was (19\%).

\footnotetext{
How to cite this article: A. K. Yawer, N. J. Abdulkader and A. A. Zainalaadbeen, "Characterization and Mechanical Properties of ZA12 Hybrid Composites Reinforced with Nano Ceramic Particles", Engineering and Technology Journal, Vol. 39, Part A, No.04, pp. 642-652, 2021.

DOI: https://doi.org/10.30684/etj.v39i4A.1945

This is an open access article under the CC BY 4.0 license http://creativecommons.org/licenses/by/4.0
}

\section{INTRODUCTION}

The materials engineering researchers have dedicated their attention for developing and creating a strong, light and less cost engineering materials. One of the main areas in developing these 
materials is a high strength / weight ratio, which are appropriate of aeronautics, automobiles and with critical issues calculated. The requirements are difficult to fulfil the use of monolithic materials [1]. Metal matrix nanocomposites (MMC) with lightweight alloy matrix and reinforced with nanoparticles or nanofibers is a promising material for gathering the requirements included. Zincbased alloys are one of the various alloys used for MMC, and for different engineering applications, these alloys became widely renowned as a cost-efficient alternative to the ferrous and the non-ferrous alloys. These alloys have remarkable properties, for example high strength, great castability and tribologically properties, corrosion resistance, low melting point, very good bearing and wear resistance properties and finally manufacturing with low cost. These composite alloys in different applications can compare popular engineering materials, like steel, cast iron, magnesium, aluminum and other reinforcement metals and alloys $[2,3,4]$. But, the main disadvantage of the ZA alloys involves high density and poor mechanical properties at elevated temperature, the loss of some properties and changes in dimensions in temperatures above $100^{\circ} \mathrm{C}$. They improved by reinforcing with ceramic dispersions, and several fibers and ceramic particles that are added to ZA alloy, creating the high-performance composites [5]. ZA-based composites were fabricated with techniques like stir casting and liquid metal infiltration.

ZA-12 alloys are appropriate for application in bearings, permanent mold and thin wall decorations. It displays a great strength, hardness, creep properties and dimensional stability [6]. Composite materials with a combination of two or more reinforcing particles increased the composite's mechanical properties. So, hybrid MMCs produced through strengthening the base matrix with more than one reinforcement to provide an excellent property $[7,8]$. B. Adaveesha et al. (2017) studied the influence of the normal load applied and the distance of sliding on the behavior of the wear of ZA43 composites alloy reinforced with (3,6 and 9) wt. \% of B4C particles, that was manufactured using the conventional stir casting technique. Results showed an enhancement in the wear rate of the ZA43 alloy reinforced with B4C particles better than the unreinforced alloy. So, with increasing the load applied and the distance of sliding, the wear rate increased [9]. R. David, et al (2018) manufactured the ZA-27 metal matrix composites composed of various weight fractions of TiC nanoparticles, as a reinforcement material. The hardness in composite materials was increased as compared to the base alloy. While, the ZA-27 provided better results with 5\% TiC nanocomposite when compared to ZA-27 with $10 \%$ TiC nano-composite, which caused an agglomerate of particles and the formation of the galvanic cell [10]. N.S. Kumar (2018) produced a hybrid composite reinforced the ZA-27 alloy with $1.5 \mathrm{wt} . \% \mathrm{SiC}$ and $0.5 \mathrm{wt}$. \% graphite, which was produced using the ultrasonic-assisted stir casting technique. To evaluate mechanical characteristics of hybrid composites as tensile strength and hardness tests were performed. When compared with the base metal, the hybrid composites mechanical properties improved. Also, for the hybrid composite the wears volume loss, reduced compared to ZA-27 alloy [11]. V. Kumar, et al. (2019) made a ZA $\mathrm{ZrB} 2$ composite using situ stir casting technique, reinforced with $(0,3,6$ and 9$)$ wt. \% ZrB2 nanoparticles. By increasing the $\mathrm{ZrB} 2$ wt. \% nanoparticles, the mechanical properties like tensile strength, wear rate, compression and hardness manifested an enhancement, while the ductility decreased [12].

The main aim of manufacturing (ZA-12) MMC material is whose zinc as well as its alloys provide a high strength to weight ratio. Also, it is increased by adding various kinds of hard ceramic particles to MMCs. The research focus on improving the microstructure and mechanical behavior of (ZA-12) alloy and its hybrid composites to further increase the utilization of MMC in the industry.

\section{MATERIALS AND METHODS}

\section{Materials Selection}

\section{A. Matrix Materials}

Zinc aluminum alloys were manufactured to be used as matrix material. Table I showed their Spectro chemical composition.

TABLE I: The ZnAl-12 alloy Spectro chemical composition. 


\begin{tabular}{ccccc}
\hline \hline Element & Zn\% & Al \% & Cu\% & $\begin{array}{c}\text { Other } \\
\text { Elements\% }\end{array}$ \\
\hline $\begin{array}{c}\text { Chemical } \\
\text { composition }\end{array}$ & 87.5 & 11.4 & 0.8 & 0.3 \\
\hline
\end{tabular}

\section{B. Reinforcing Materials}

Boron nitride and silicon carbide used as reinforcement nanoparticles for ZA-12 alloys. By using Scanning Electron Microscopy (SEM), the morphology of ( $\mathrm{SiC}$ with $50 \mathrm{~nm}$ which was produced by Hefei EV nano technology/ China) and (BN with $35 \mathrm{~nm}$ which was produced by Nano shield technology/ USA) were obtained and shows in Figure 1.

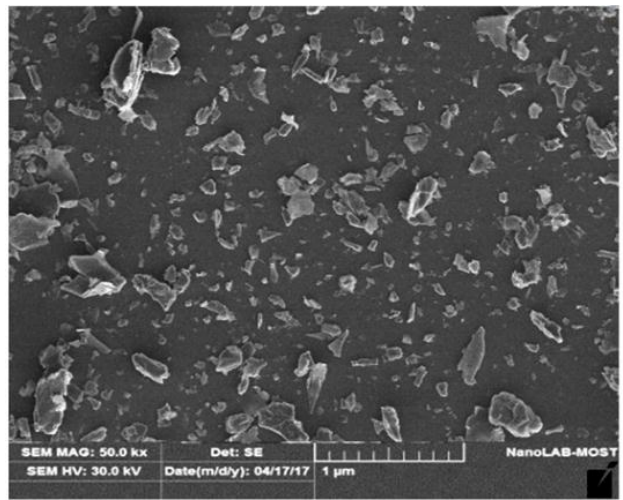

(a) Nano $\mathrm{SiC}$

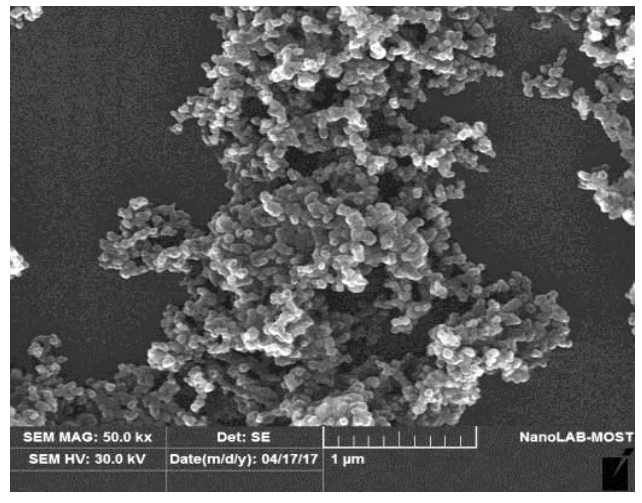

(b) Nano BN

Figure 1: (a) and (b) shows the SEM of the SiC and BN nano powders.

\section{Production of Matrix Material:}

In the manufacturing process of the (ZA-12) alloy, aluminum scrap (AA 2024), pure Al (electrical wires) and zinc scraps (pure) were molten within a graphite crucible, an electrical furnace up to around $700^{\circ} \mathrm{C}$ (above melting temperature) was used to achieve the maximum melting. Then, it was mixed with a mechanical stirrer made of stainless steel forming a homogeneous mixture. With using 0.25 wt. \% cleaning fluxing $(\mathrm{KCl}-\mathrm{NaCl}-\mathrm{NaF})$ was used. which is mainly rich in chlorides to promote the oxide inclusions wetting for easy and fast separation from of the melt. Hexachloroethane has been used to degases the melt to really throw away the gases and the contaminants.

The $(\mathrm{SiC}$ and $\mathrm{BN})$ reinforcement nanoparticles with different weight percent $(2 \%, 3 \%)$ were applied as wrapped in aluminum foil to the melted matrix and stirred continuously with a mechanical stirrer for $(2-3)$ times and (1000-1200) r.p.m speed. Then removed the slags, and also poured the molten liquid into a specific mold. The castings have been removed from the mold just after solidification, and shaped into the required shapes. Figure 2 and 3 display the preparation of the mold and the ZA-12 alloy specimens with different weight percentage of nano particles reinforcement, respectively. Figure 4 shows the graphite crucible and the Stir casting furnace. 


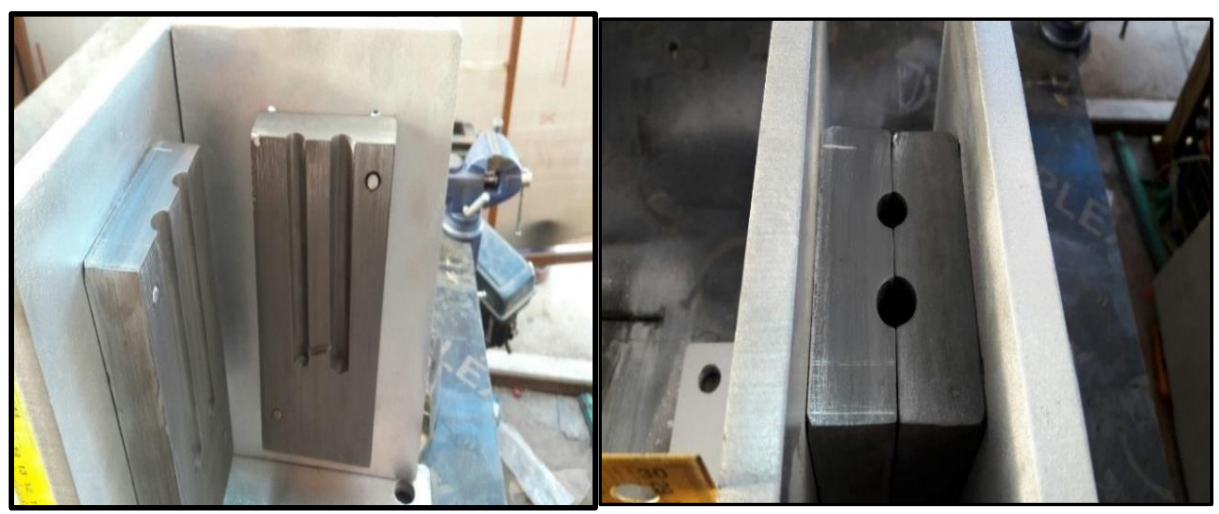

Figure 2: Preparation of the mold.

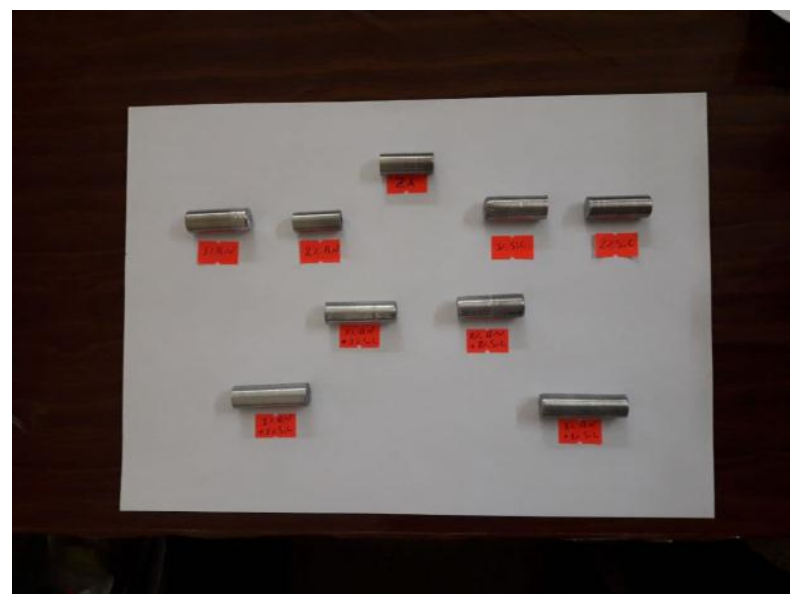

Figure 3: The ZA- 12 alloy specimens with different weight percentage of nano particles reinforcement.

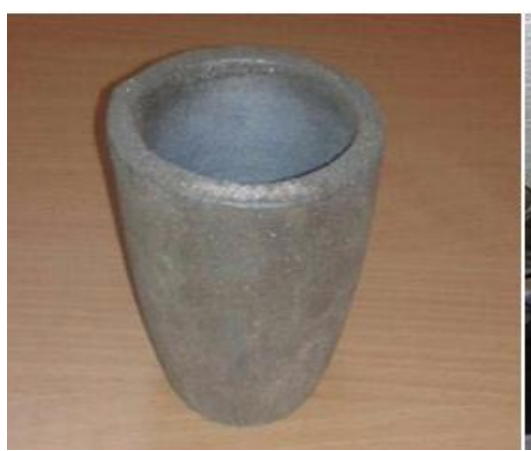

Graphite crucible

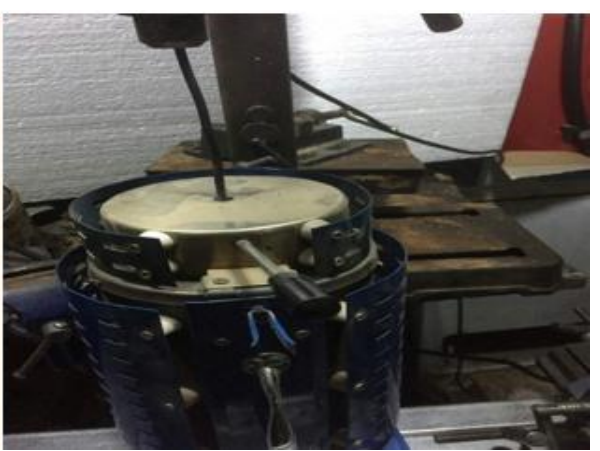

Electric furnace

Figure 4: The graphite crucible and the Stir casting furnace.

\section{Mechanical Tests:}

A. Hardness test:

Digital Vickers Macro hardness analyzer was used to measure the hardness of the composite. All specimens were prepared with $\mathrm{SiC}$ grinding sheet up to $800 \mu \mathrm{m}$ and afterwards polished by using 5 $\mu \mathrm{m} \mathrm{Al}_{2} \mathrm{O}_{3}$ powder (slurry), and the average value of three readings was taken at different spots on the surface of specimen. which were done by an applying load of $(294 \mathrm{~N})$ for $(10 \mathrm{sec}$.).

\section{B. Compression Test:}

Compression testing was used to estimate the strength of the compression. The specimen of compression is a cubic or cylindrical item. Specimens were standard as per of (ASTM E-9) [13] with (10 $\mathrm{mm}$ diameter and $25 \mathrm{~mm}$ height). The rate of strain was $(0.5 \mathrm{~mm} / \mathrm{min})$. The test was conducted 
with a computer-controlled universal electronic test machine (wdw-50) and the specimen of compression was a cylindrical item.

C. Wear Test:

A dry sliding wear experiment for (ZA-12) alloy reinforced with nano-boron nitride (BN) and nano-silicon carbide $(\mathrm{SiC})$ was performed by using a pin on disc wear device according to the standard (ASTM G99-95) [14]. Dimensions of the specimen were $(\varnothing 10 \mathrm{~mm})$ with length $(30 \mathrm{~mm})$. The test was conducted by applying a load of $(10,20,30) \mathrm{N}$. The disk potential velocity was $(950$ $\mathrm{rpm})$. The sliding distance $(65 \mathrm{~mm})$ and for $(15 \mathrm{~min})$. The disk is manufactured from stainless steel with a hardness of (55 HRC). Then, Eq. (1) was used to calculate the wear rate from the mass loss slope per sliding distance [15].

$$
\mathrm{W} . \mathrm{R}=\frac{\Delta \mathrm{W}}{2 * \pi * \mathrm{r} * \mathrm{n} * \mathrm{t}}
$$

Where:

$W . R$ : Rate of wear $(\mathrm{g} / \mathrm{cm})$.

$\Delta W$ : Weight loss, as $\Delta W=W_{I^{-}} W_{2}$.

$\mathrm{W}_{1}$ : Weight before testing $(\mathrm{g})$.

$\mathrm{W}_{2}$ : Weight after testing $(\mathrm{g})$.

$r$ : Distance of Sliding $(\mathrm{cm})$.

$n$ : Disk rotational speed in (r.p.m.).

$t$ : time 15 ( $\mathrm{min})$.

\section{Microstructure:}

The surface morphology was tested using the optical microscope (Optika 1000) to analyze the microstructure and the phases formulated. So, all the spacemen were prepared after etching them using a Keller solution ( $3 \mathrm{ml} \mathrm{HF}, 6 \mathrm{ml} \mathrm{HNO}_{3}$, and $\mathrm{H}_{2} \mathrm{O}$ ) [16].

As well, scanning electron microscope (SEM) of the base alloy and its composite were used employing (Inspect S 50 device). The magnification used on spacemen range within (100-20000X) respectively.

\section{RESULTS AND DISCUSSION}

\section{Hardness Measurement:}

The macro hardness values for Vickers are depicted in the Figure 5. Table II shows the hardness values of the ZA-12 alloy and its composites. Results appeared that when the percentage of nanoparticles increased, the hardness of both the matrix material and its composites increased. The composite's load-bearing capacity increased whenever the hard-ceramic reinforcing particles (BN and $\mathrm{SiC}$ ) are available in the matrix and restricts the deformation of the matrix through obstructing the movement of dislocation. The increase in hardness could be due to the reduction in the grain size and the increase in content $(\mathrm{BN}$ and $\mathrm{SiC})$ particles $[16,17]$. Based on the fact that the nanoparticles in samples act effectively to reinforce the (ZA-12) matrix. Maximum hardness values were recorded at $(3 \% \mathrm{BN}+3 \% \mathrm{SiC})$ weight fraction with an enhancement ratio of $26 \%$. Table III shows the enhancement percentage of the hardness for each reinforcement.

TABLE II: The hardness values of the ZA-12 alloy and its composites.

\begin{tabular}{ccc}
\hline No. The ZA12 alloy with different weight percentage & $\begin{array}{c}\text { Hardness } \\
\text { of nano particles reinforcement } \\
\text { H.V } \\
\left(\mathbf{k g} / \mathbf{m m} \mathbf{m}^{\wedge}\right)\end{array}$ \\
\hline 1 & $\mathrm{ZA}-12$ & 104 \\
\hline 2 & $\mathrm{ZA}-12+2 \% \mathrm{BN}$ & 113 \\
\hline 3 & $\mathrm{ZA}-12+2 \% \mathrm{SiC}$ & 115.8 \\
\hline 4 & $\mathrm{ZA}-12+2 \% \mathrm{BN}+2 \% \mathrm{SiC}$ & 122.3 \\
\hline 5 & $\mathrm{ZA}-12+3 \% \mathrm{BN}+3 \% \mathrm{SiC}$ & 131 \\
\hline
\end{tabular}




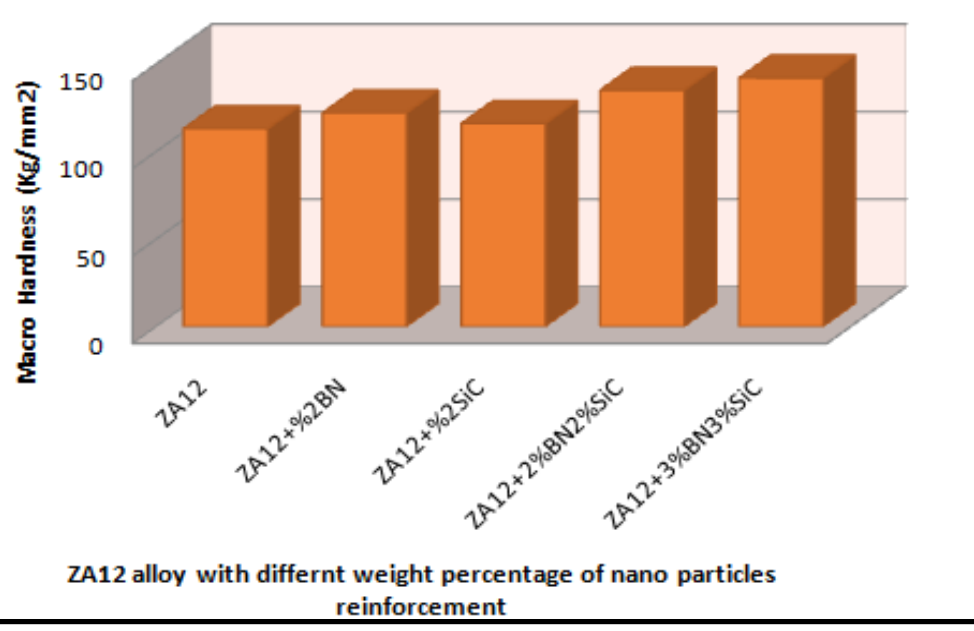

Figure 5: Hardness values of the ZA-12 alloy and its composites.

TABLE III: The enhancement percentage of the hardness for each reinforcement

\section{No. The ZA12 alloy with different weight percentage of nano particles reinforcement}

\begin{tabular}{ccc} 
& & hardness \\
\hline 2 & ZA-12+2\%BN & $8.7 \%$ \\
\hline 3 & ZA-12+2\% SiC & $11.3 \%$ \\
\hline 4 & ZA-12+2\%BN+2\%SiC & $17.6 \%$ \\
\hline 5 & ZA- $12+3 \% \mathrm{BN}+3 \% \mathrm{SiC}$ & $26 \%$ \\
\hline
\end{tabular}

\section{Compression Test:}

For ZA-12 alloy and its composites, the compressive strength was tested at room temperature, as shown in the Figure 6. After applying the compression load on the specimen, the results showed a decrease in the length of specimen until the deformation of the brittle specimen became at the load capacity as shown in Figure 7. As the nanoparticle's reinforcement started to increase, the compressive strength of ZA-12 alloy, as well as its composites, often increased. Because of the decrease in the matrix grain size, the uniform distribution, the stronger $\mathrm{BN}$ and $\mathrm{SiC}$ particles in the ductile matrix, and a confirmed improvement in compressive strength occurred. The effect of Orowan strengthening may be another source for strengthening in composites. Also, the load shift from the matrix to the particles plays a main role. The addition of $\mathrm{BN}$ and $\mathrm{SiC}$ particles avoids the cracking during the loading and may enhance the strength $[12,16]$. In general, the stirred alloy compression became greater than non-stirred alloy, and with a grain size reduction in the metallic materials, the hardness and the strength increased [18]. Table IV shows the compression values of ZA-12 alloy and its composites.

TABLE IV: The compression values of ZA-12 alloy and its composites

\begin{tabular}{ccc}
\hline No. The ZA12 alloy with different weight percentage & $\begin{array}{c}\text { compressive } \\
\text { of nano particles reinforcement } \\
\text { strength } \\
\text { values }\end{array}$ \\
\hline 1 & $\mathrm{ZA}-12$ & 825 \\
\hline 2 & $\mathrm{ZA}-12+2 \% \mathrm{BN}$ & 860 \\
\hline 3 & $\mathrm{ZA}-12+2 \% \mathrm{SiC}$ & 840 \\
\hline 4 & $\mathrm{ZA}-12+2 \% \mathrm{BN}+2 \% \mathrm{SiC}$ & 870 \\
\hline 5 & $\mathrm{ZA}-12+3 \% \mathrm{BN}+3 \% \mathrm{SiC}$ & 980 \\
\hline
\end{tabular}




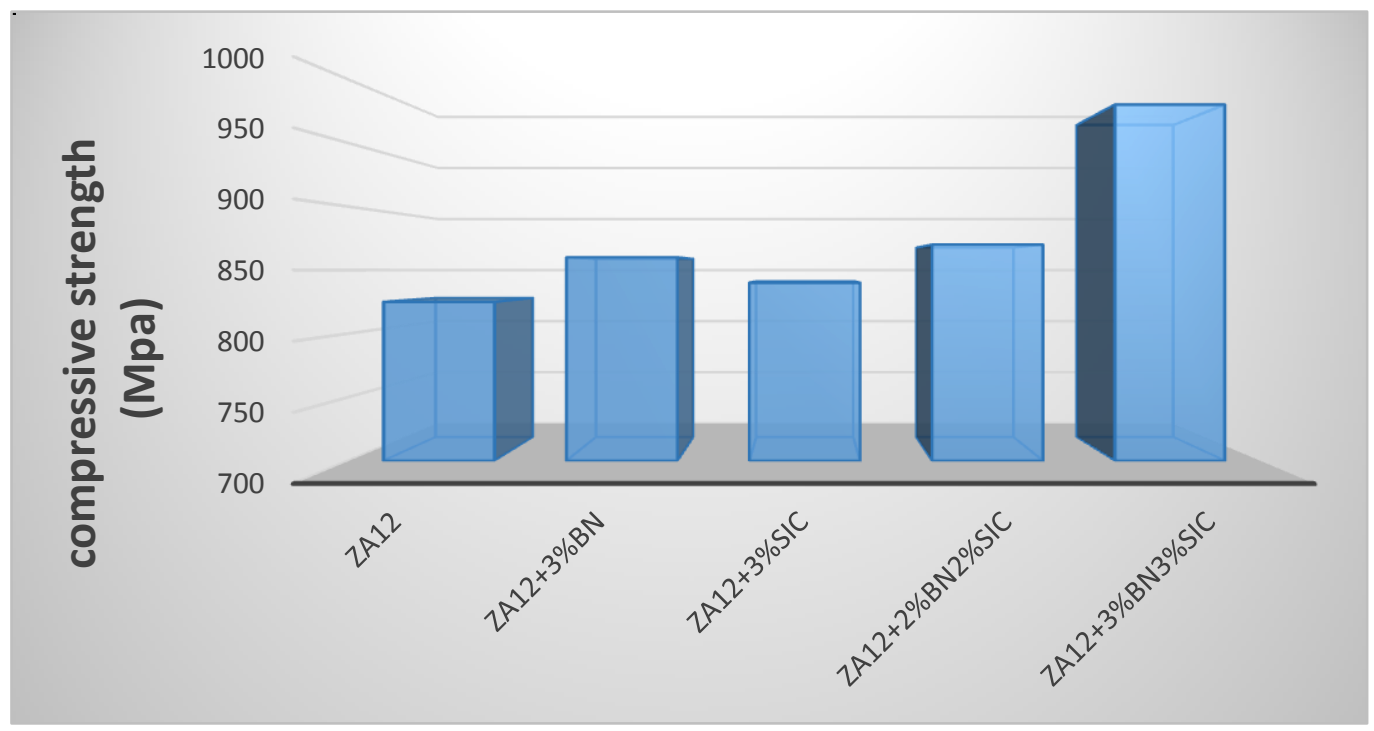

Figure 6: Compression values of ZA-12 alloy and its composites

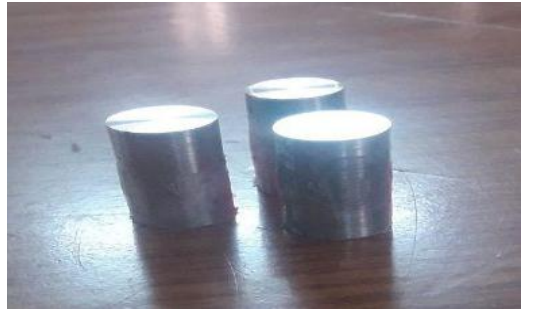

(A) Before compression test

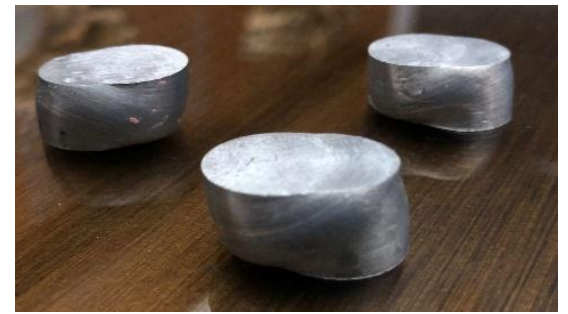

(B) After compression test

Figure 7: Compression specimens

\section{Wear test:}

Wear test was performed for (ZA-12) alloy, and showed that the wear rate was decreased in the composite specimen with the nanoparticle additives increased, as shown in Figure 8. Moreover, when the load is increased, the increase in wear is observed, revealing the transition of mild wear to severe wear. The minimum wear loss was observed for ZA-12/ $(3 \% \mathrm{BN}+3 \% \mathrm{SiC})$ reinforcement when compared to the other composite materials studied at different loads as shown in Table V. The wear rate decreased for all composites with increasing nanoparticles when compared to the base alloy. Those were the result of the presence of both reinforcing materials, which are assumed to form a stable film on surface composites [11, 12, 19]. The nano ceramic particles could improve the hardness and the wear properties of composite and help in the formation of a stable tribolayer.

.TABLE V: Wear rate values for ZA-12 alloy and its composites at different loads.

\begin{tabular}{|c|c|c|c|c|}
\hline \multirow[t]{2}{*}{ No. } & \multirow{2}{*}{$\begin{array}{c}\text { The ZA12 alloy with different } \\
\text { weight percentage of nano } \\
\text { particles reinforcement }\end{array}$} & \multicolumn{3}{|c|}{$\begin{array}{c}\text { Wear Rate }(\mathrm{gm} / \mathrm{cm}) * 10^{\wedge}-8 \\
\text { At different loads }(\mathrm{N})\end{array}$} \\
\hline & & $10(\mathrm{~N})$ & $20(\mathrm{~N})$ & $30(\mathrm{~N})$ \\
\hline 1 & ZA-12 & 2.2 & 4.5 & 5.8 \\
\hline 2 & $\mathrm{ZA}-12+2 \% \mathrm{BN}$ & 1.5 & 4.1 & 5.5 \\
\hline 3 & $\mathrm{ZA}-12+2 \% \mathrm{SiC}$ & 1.9 & 3.7 & 5.2 \\
\hline 4 & $\mathrm{ZA}-12+2 \% \mathrm{BN}+2 \% \mathrm{SiC}$ & 1.2 & 3.5 & 5 \\
\hline 5 & $\mathrm{ZA}-12+3 \% \mathrm{BN}+3 \% \mathrm{SiC}$ & 1 & 3 & 4.7 \\
\hline
\end{tabular}




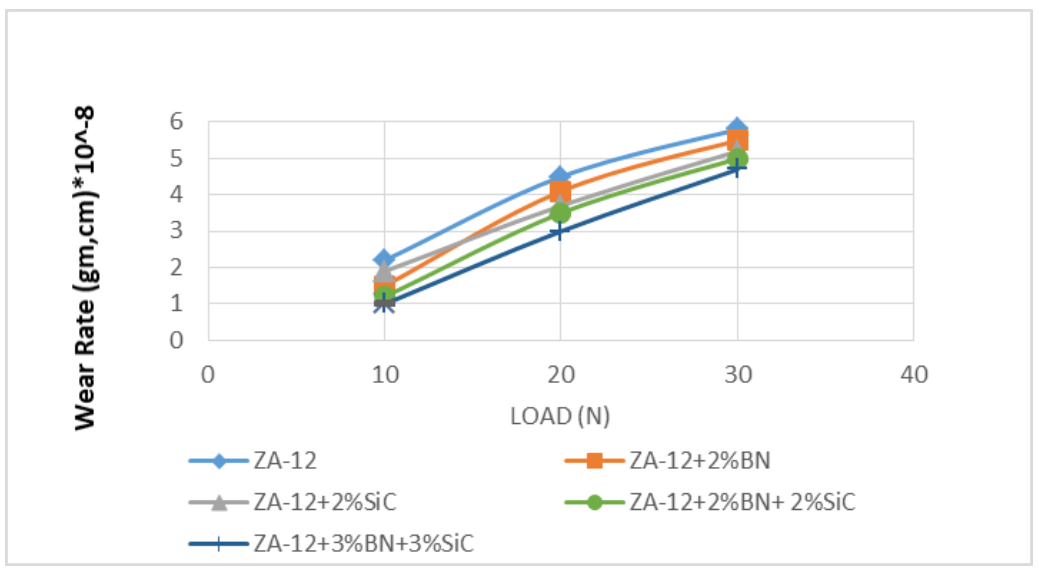

Figure 8: Wear rate values for ZA-12 alloy and its composites at different loads.

\section{Microstructure Analysis:}

An optical microscope and Scanning electron microscope (SEM)/(TESCAN type) were used to analyze the microstructure and any phases formed. Besides, it proved great dispersion of reinforcement in the matrix. When nanoparticles weight percent of the matrix is increased, the particles of reinforcement increased and the interparticle space decreased. The microstructure seems to be dendritic; the considered dendrites fragmented by mechanical stirring. Which describes the potential enhancement of the nano-sized particles incorporated. Also, the entrapment inside the interdendritic interface, enhanced through the solidification of such dispersed alloys [20, 19], as seen in Figure 9.

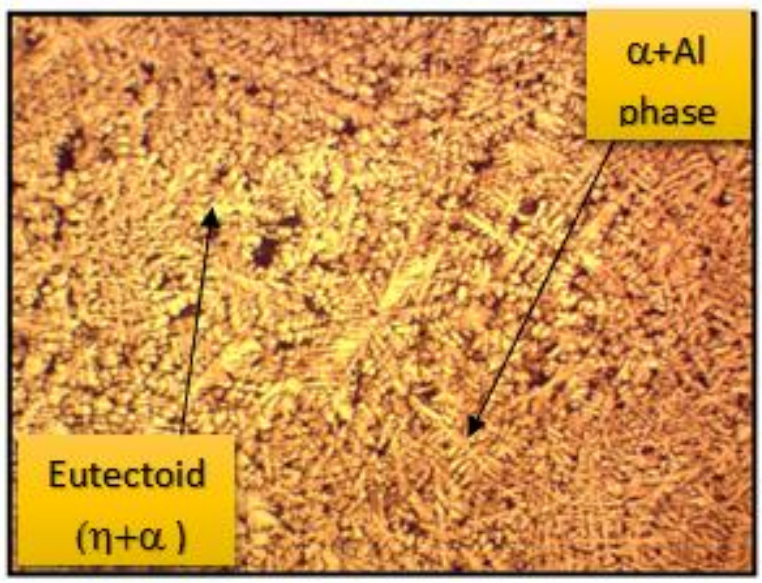

a) ZA-12 alloy

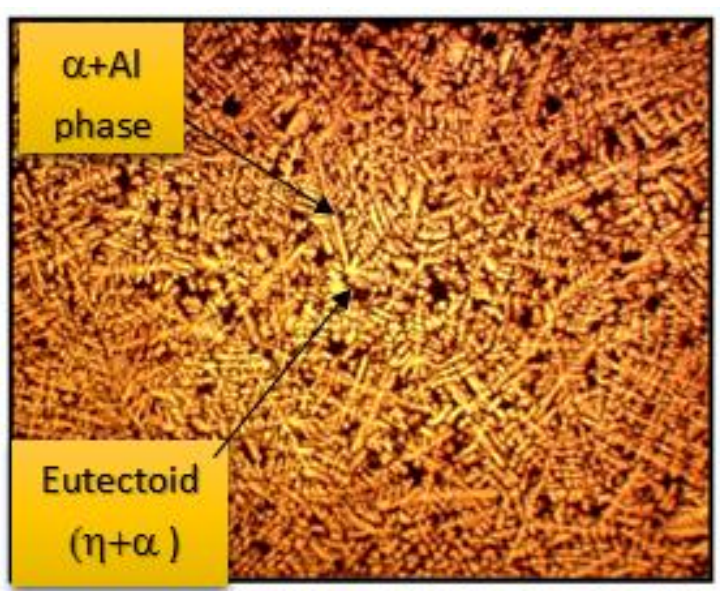

b) ZA-12 alloy $+3 \%$ BN

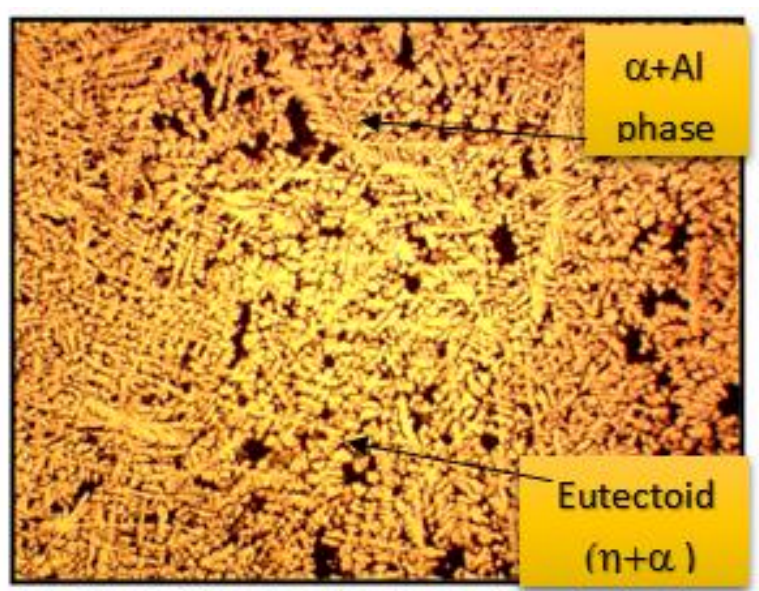

c) ZA-12 alloy 


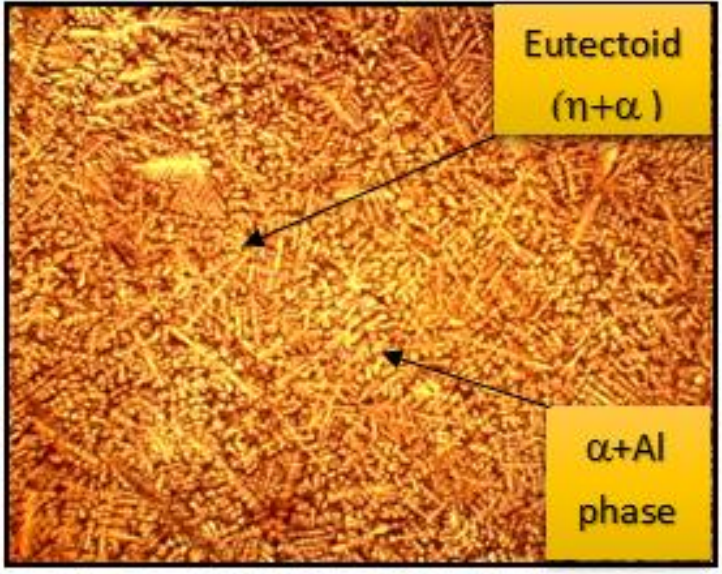

$+3 \% \mathrm{SiC}$

d) $\mathrm{ZA}-12$ alloy $+2 \% \mathrm{BN}+2 \% \mathrm{SiC}$

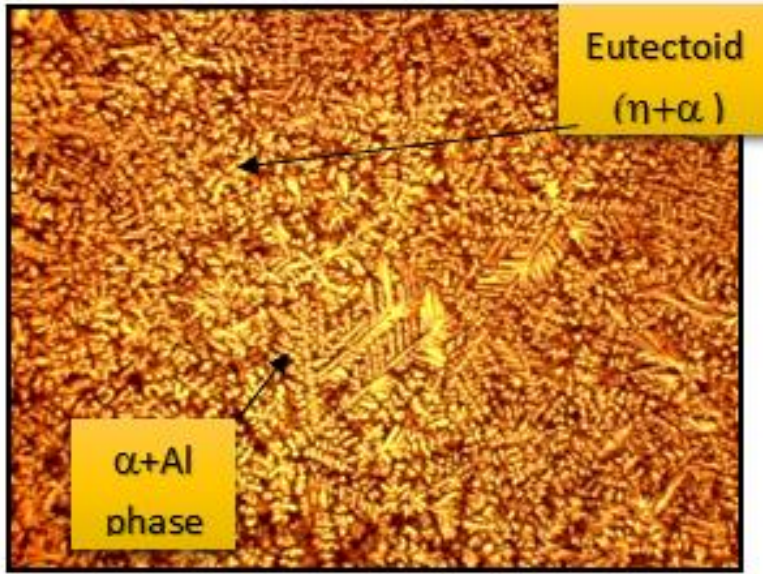

e) $\mathrm{ZA}-12$ alloy $+3 \% \mathrm{BN}+3 \% \mathrm{SiC}$

Figure 9: The ZA-12 alloy microstructure of the matrix with the percent of nano particles at different weight and a magnification power of (10x).

The Figure 10 displays the SEM microstructure of the ZA-12 hybrid nanocomposites. From microstructure of the processed nanocomposites, it is appeared that the hybrid nanoparticles (BN) and $(\mathrm{SiC})$ equally dispersed in the ZA-12 matrix.

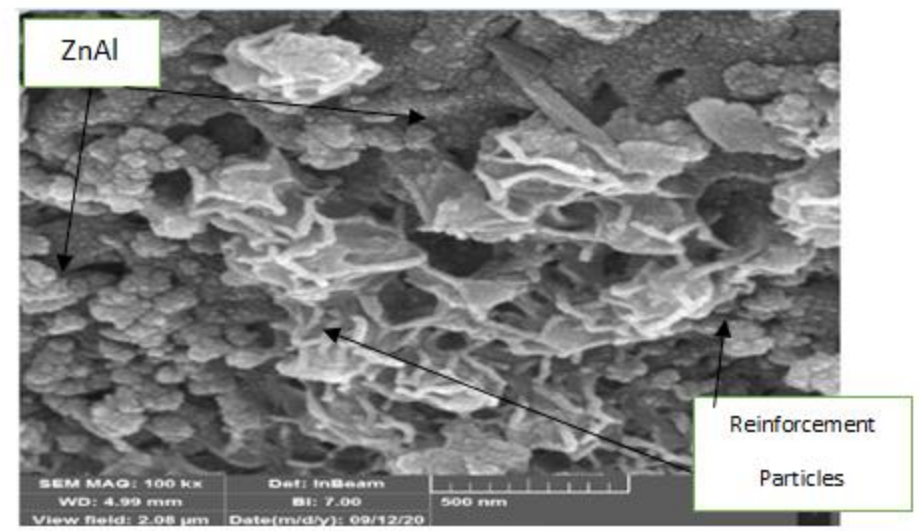

$\mathrm{A}-\mathrm{ZA}-12$ alloy $+2 \% \mathrm{BN}+2 \% \mathrm{SiC}$

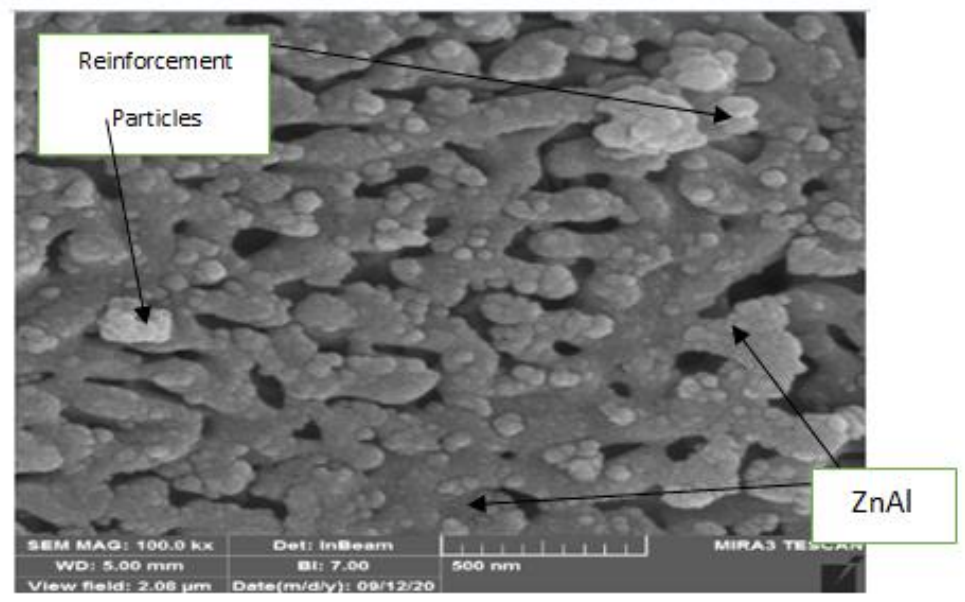

B- ZA-12 alloy $+3 \% \mathrm{BN}+3 \% \mathrm{SiC}$

Figure 10: (A, B): The SEM microstructures of $\mathrm{BN}$ and $\mathrm{SiC}$ nano-particles at different weight percentages in the ZA-12 alloy 


\section{CONCLUSIONS}

The followings can be concluded from the tests and characterization results: The ZA-12 alloy can be manufactured efficiently, simply and with low-cost from the recycled alloy by stir casting techniques. The microstructure and SEM analysis showed that the particles distributed uniformly in the base matrix-supported with the weight percentages of nano reinforcement ( $\mathrm{BN}$ and $\mathrm{SiC}$ ) explaining the mechanical properties enhancement. The addition of hybrid nanoparticles (BN and $\mathrm{SiC})$ improved the mechanical properties of the ZA-12 alloy. The highest hardness was achieved at the $\mathrm{ZA}-12 /(3 \% \mathrm{BN}+3 \% \mathrm{SiC})$ composite. The improvement ratio in hardness after addition was $26 \%$. The optimum wear results gained at $(3 \% \mathrm{BN}+3 \% \mathrm{SiC})$ particle reinforcement composite manifested an increase up to $(24 \%)$ acquired for the $\mathrm{ZA}-12 /(3 \% \mathrm{BN}+3 \% \mathrm{SiC})$ composite comparing to base alloy ZA-12. Compared to the base alloy, the highest compression strength was at ZA-12/ (2 \% BN+3\% $\mathrm{SiC})$ composite with an improvement of (19\%).

\section{References:}

[1] B. O. Fatile, B. O. Adewuyi, and H. T. Owoyemi, "Synthesis and characterization of ZA-27 alloy matrix composites reinforced with zinc oxide nanoparticles", Engineering Science and Technology: An International Journal, Vol. 20, No. 3, PP. 1147-1154, 2017.

[2] M. O. Bodunrin, K. K. Alaneme, and L. H. Chown. "Aluminium matrix hybrid composites: a review of reinforcement philosophies; mechanical, corrosion and tribological characteristics", Journal of Materials Research and Technology, Vol. 4, No. 4, PP. 434-445, 2015.

[3] D. Patidar, and R. S. Rana, "Effect of B4C particle reinforcement on the various properties of aluminium matrix composites: a survey paper", Materials Today: Proceedings, Vol. 4, No. 2, PP. 2981-2988, 2017.

[4] O. Güler, M. Çelebı, R. Dalmış, A. Çanakçi and H. Çuvalci, "Novel ZA27/B 4 C/graphite hybrid nanocomposite - bearing materials with enhanced wear and corrosion resistance", Metallurgical and Materials Transactions A, Vol. 51, No.9, PP.4632-4646., 2020.

[5] S. K. Mishra, B. Sandhyarani, and A. Satapathy, "A study on processing, characterization and erosion wear behavior of silicon carbide particle filled ZA-27 metal matrix composites", Materials \& Design, Vol. 55, PP. 958-965, 2014.

[6] D. A. Khan, and D. P. Mondal, "Effect of strain rate and temperature on deformation behavior of closed-cell ZnAl12 hybrid foam", Materials Research Express, Vol. 5, No. 11, PP. 116507, 2018.

[7] E. Mosisa, V. Y. Bazhin and S. Savchenkov, "Review on nanoparticle reinforced aluminum metal matrix composites", Research Journal of Applied Sciences, Vol. 11, No.5, PP. 188-196, 2016.

[8] M. A. Xavior and J. A. Kumar, "Machinability of hybrid metal matrix composite-A review", Procedia Engineering, Vol. 1, No. 174, PP.1110-1118, 2017.

[9] B. Adaveesh, G. M. Halesh, and V. Kumar, "Investigations on dry sliding wear behavior of b4c reinforced za43 alloy composites", Materials Today: Proceedings, Vol. 4, No. 10, PP. 10957-10964, 2017.

[10] R. David, V. Shrivastava, R. Dasgupta, B. K. Prasad, and I. B. Singh, "Corrosion investigation of zincaluminum alloy (ZA-27) matrix reinforced with in situ synthesized titanium carbide particle composites.", Journal of Materials Engineering and Performance, Vol. 28, No. 4, PP. 2356-2364, 2019.

[11] N. S. Kumar, "Mechanical and wear behavior of ZA-27/Sic/Gr hybrid metal matrix composites", Materials Today: Proceedings, Vol. 5, No. 9, PP. 19969-19975, 2018.

[12] V. Kumar, A. Mishra, S. Mohan, and A. Mohan, "Fabrication of stir cast ZA/ZrB 2 reinforced in-situ composites", Materials Research Express, Vol. 6, No. 12, PP. 126555, 2019.

[13] ASTM, E9. "Standard test methods of compression testing of metallic materials at room temperature." West Conshohocken, PA: ASTM International, PP.98-105, 2000.

[14] W. Conshohocken, "Standard test method for wear testing with a pin-on-disk apparatus 1", Vol. 5, PP.1-5, 2000.

[15] M. Abbass, and M. Fouad, "Wear characterization of aluminum matrix hybrid composites reinforced with nanoparticles of $\mathrm{Al}_{2} \mathrm{O}_{3}$ and $\mathrm{TiO}_{2}$ ", Journal of Materials Science and Engineering, Vol. 5, No. 9, PP. 361-371, 2015. 
[16] S. S. Owoeye, D. O. Folorunso, B. Oji, and S. G. Borisade, "Zinc-aluminum (ZA-27)-based metal matrix composites: a review article of synthesis, reinforcement, microstructural, mechanical, and corrosion characteristics." The International Journal of Advanced Manufacturing Technology, Vol. 100, No. 1-4, PP. 373380, 2019.

[17] T. S. Kiran, M. P. Kumar, S. Basavarajappa, and B. M. Vishwanatha, "Mechanical properties of as-cast za27/gr/SiCp hybrid composite for the application of journal bearing", Journal of Engineering Science and Technology, Vol. 8, No. 5, PP.557-565, 2013.

[18] O. Torun, and I. Celikyurek, "Effect of stirring on the microstructure and mechanical properties of zamak12 alloy", The Eurasia Proceedings of Science Technology Engineering and Mathematics, Vol. 7, PP. 136-140, 2019.

[19] X. Canute and M. C. Majumder, "Mechanical and tribological behavior of stir cast aluminum/boron carbide/fly ash composites", Journal of Engineering Sci. and Technol, Vol. 13, No. 3, PP. 755-777, 2018.

[20] D. O. Folorunso, and S. S. Owoeye, "Influence of quarry dust-silicon carbide weight percentage on the mechanical properties and tribological behavior of stir cast ZA-27 alloy-based hybrid composites", Journal of King Saud University-Engineering Sciences, Vol. 31, No. 3, PP. 280-285, 2019 